\title{
Factors of academic stress: Do they impact English academic performance?
}

Erlinda D. Tibus, Sybill Krizzia G. Ledesma

College of Teacher Education, Southern Leyte State University, Philippines

\begin{tabular}{l} 
Article Info \\
\hline Article history: \\
Received Jan 15, 2021 \\
Revised Aug 10, 2021 \\
Accepted Sep 14, 2021 \\
\hline
\end{tabular}

\section{Keywords:}

Academic stress

EFA

English academic performance

Factors of academic stress

Parallel analysis

\begin{abstract}
This study investigated the college students' level of academic performance and determined the impact of academic stress on their English academic performance. This employed a descriptive-exploratory research design with Exploratory Factor Analysis (EFA) and correlation analysis (Pearson r) as main analyses using statistical software. The result suggested that the students $(\mathrm{N}=250)$ have a moderate level of stress. Likewise, seven factors were generated through EFA but were reduced to four factors using parallel analysis, the factors are perceived personal stress, classroom stress, performance stress, and time management stress. In the correlation analysis, it was found out that perceived personal stress, classroom stress, and performance stress are significantly correlated except for time management stress. Moreover, these factors were found to have no significant relationship with the English grades of the students. With this result, it is concluded that despite having a moderate level of academic stress, students were able to manage them by using a plethora of coping mechanisms available. The institutions should offer prevention and intervention services that directly address the academic stress of the students to ensure academic success.
\end{abstract}

This is an open access article under the $\underline{C C B Y-S A}$ license.

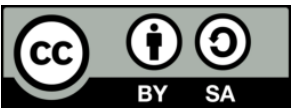

\section{Corresponding Author:}

Sybill Krizzia G. Ledesma

College of Teacher Education

Southern Leyte State University

San Isidro, Tomas Oppus, Southern Leyte, 6605, Philippines

Email: sybillkrizzia@slsuonline.edu.ph

\section{INTRODUCTION}

Stress is defined as a condition in which a person's potentials are threatened to be exceeded [1]. When the individual's resources to cope with their circumstance are exhausted due to a mix of internal and external pressures, stress results. Stress can disrupt a student's learning and memory, and as a result, it has the potential to harm academic performance.

It is a typical occurrence for students to communicate with their surroundings, whether individually or in groups, and for these constant contacts with the environment to influence their academic performance in some way. Academic stress among students has been a hot topic among students for some years. This is a topic that academics and other researchers are deeply concerned about. Some people believe that stress is harmful and that they will go to great lengths to avoid it. However, Yates [2] believed that the correct amount of stress is an important part in anyone's life who wants to remain vibrant. Stress is managed rather than avoided. Likewise, Ivancevich and Matteson [3] indicated that stress does not always lead to a drop in performance. They claimed that there is a certain amount of stress that may be tolerated in order to achieve good results. An ideal degree of stress can improve one's abilities, lead to peak efficiency, provide happiness, a sense of well-being and accomplishment, as well as other success rewards. However, too much stress can 
lead to physical and mental health issues, lower self-esteem, and negatively impact pupils' academic performance [4].

Aafreen, Priya, and Gayathri [4] discovered that when people are anxious, their bodies immediately believe they are being attacked and go into "fight or flight" mode, releasing a complex combination of hormones and chemicals including adrenaline, cortisol, and norepinephrine to prepare them for physical action. This results in a variety of reactions, including blood being directed to muscles and unneeded body activities, such as digestion, being turned off.

Some stressors exist both inside and beyond the school environment, causing stress. Stress is a common concern for most students in their academic lives because it might affect their academic performance. Students undoubtedly endure stress as a result of circumstances such as academic commitments and duties, financial challenges, poor time management skills, and so on. According to Pariat, et al. [5], academic stress is a tangible product of a transaction between a student's cognitive evaluation and environmental stressors or expectations associated with academic contexts. Anxiety, inefficient time management, a lack of rewarding extracurricular activities, financial troubles, sleep deprivation, social activities, and other variables that students perceive as risks to their academic success are among the possible stressors [6]. The study of Shaikh, et al. [7] found that academics and examinations are the most common sources of stress for pupils. Wilks [8] warned that if a student fails to manage successfully one's academic stress, substantial psychosocial and mental health implications could follow.

For the majority of teenagers, school is the best time of their lives. Depression, anxiety, and stress may all cause problems on these formative years. Students are likely to face a variety of pressures that will put their capacity to cope to the test, including adjusting to a new environment, balancing a high task, making new friends, growing more independent, and dealing with a variety of other challenges.

According to Gbollie and Keamu [9], students' academic performance varies at different levels because they are driven by motivation. Students are equipped with varied abilities because they came from various institutions that provide distinct training. Hence, students' academic performance varies at different levels because they are driven by motivation. Some pupils excel academically, while others struggle, and still others are ordinary. Some schools are ahead of the curve, while others lag far behind, resulting in major differences in student academic performance. Academic performance refers to a student's, teacher's, or institution's achievement of an educational goal over a period of time. College students face numerous challenges in order to attain their best academic results. To have a successful college career, one must do more than just study hard.

This study investigated the level of academic stress of college students in a university and its impact on their academic performance. Ajzen's Theory of Planned Behavior illustrates that actions are projected proximally from one's intentions to participate in the behavior. These intentions are then predicted from three other characteristics known as: i) Perceived behavioral control described as the subjective capacity to easily act; ii) Attitudes or evaluations of the valence of behavior; and iii) Subjective norms or perceived social pressure to carry out the action or to abstain from acting out the behavior [10]. More so, Shadi, et al. [11] highlighted that the theoretical structures of this theory have been shown to be able to predict intention and, as a result, behavior. The primary motivation for engaging in a particular activity is to do so, which might increase students' stress levels in the classroom and have an impact on their English academic performance. The attitude toward the behavior and the mental norms linked with that activity determine an individual's behavioral intention. To put it another way, an individual's conduct is influenced by his or her attitude toward the behavior, which influences one's willingness to engage in specific behaviors.

\section{RESEARCH METHOD}

This study employed a descriptive-exploratory research design. This research design described the results of the factors generated using the Exploratory Factor Analysis (EFA) and explored whether the factors were correlated and significantly impacted the English academic performance of the college students. EFA was used in this study as a statistical tool to categorize the fewer number of factors which can be explained by the correlation among the set of consistent variables. Likewise, the overall objective of the EFA was data summarization and data reduction. Its central aim was to systematically simplify several interrelated measures and describe the data using the generated fewer dimensions than the original variables. This was an effective technique to extract maximum common variance from all the variables and put them into a common score. Factor loadings measured the degree of relationship between indicators and their factors. Besides, correlation analysis (Pearson r) was used to test if the factors have correlation, or if factors were significantly correlated.

The instrument used was the Academic Stress Inventory (ASI) which was adapted from the Questionnaire of Academic Stress (QAS) of Garcia-Ros, Perez-Gonzalez, and Tomas [12]. The QAS focused 
on investigating the students' everyday stressors in the context of the school, such as those pressures they get from schoolwork, worries about school achievement, difficulties with peers at school, conflicts with teachers and parents, and concerns about the future and their effects on adolescents' well-being. The QAS was comprised of thirty items related to different potentially stress-producing situations at the college level. The ASI was sent to college students $(\mathrm{N}=250)$ of this university using an online platform. Student's responses revealed their stress level in the different school situations on a Likert-type scale with five response options ( $1=$ "Very low" to 5="Very high"). Moreover, they also shared their grade percentage average (GPA) in all their major subjects to be used to determine the influence of academic stress on the English academic performance of the students. The data through an online platform was generated and analyzed using statistical software.

To identify if the data was already adequate for factor analysis, Kaiser Meyer Olkin (KMO) was used. This measure varied between 0 and 1 , and the values closer to 1 were better. A value of .6 was a suggested minimum. Moreover, to identify if the variables had acceptable correlations between each other, data were treated through Bartlett's Test of Sphericity for Factor Analysis to be recommended suitably.

Using exploratory analysis with the principal component extraction method, seven factors were generated; however, seven factors seemed too many, so the parallel analysis was conducted to determine if the number of factors can further be reduced from seven. With parallel analysis, four factors were retained from the previous seven generated factors.

\section{RESULTS AND DISCUSSION}

The results of the computation of the data using factor and parallel analyses and the factors generated through these statistical tools are presented here. Likewise, the level of academic stress among college students and the result of the correlation analysis were presented and comprehensively discussed, respectively.

\subsection{Factors of academic stress among college students}

To measure whether it is acceptable to proceed to factor analysis, data were first treated using the Kaiser Meyer Olkin (KMO) Measure of Sampling Adequacy and Bartlett's Test of Sphericity. In KMO, high values should be close to 1.0 but not less than 0.50 to identify whether factor analysis may be useful with the data. Through this test, it was identified that the sampling of this study was adequate for further analysis with a 0.857 result.

Furthermore, for variables to be reduced to a smaller number of components, there should be adequate correlations between variables. In this study, data were tested through Bartlett's Test of Sphericity which should have resulted in less than 0.05 for factor analysis to be recommended suitably. More so, the suitability of the data for structure detection is shown in Table 1. Meanwhile, the eigenvalues and percent variance explained based on the Kaiser criterion are presented in Table 2. Moreover, the scree plot as in Figure 1 is shown to further support the result of the analysis.

The eigenvalues and percentage variance using Kaiser-criterion and reinforced by the scree plot show that there are seven generated factors. Notice that the number of factors generated was significantly many; hence, further analysis was conducted. To finally get the factors essential for the succeeding analyses, the parallel analysis was used to reduce the seven generated factors. The result of the parallel analysis is shown in Table 3. It shows that there are four factors of stress to be retained to be used in the correlation analysis.

Table 1. KMO and Bartlett's test

\begin{tabular}{ccc}
\hline \multicolumn{2}{c}{ Kaiser-Meyer-Olkin measure of sampling adequacy } & .857 \\
\hline Bartlett's test of sphericity & Approx. Chi-Square & 3040.382 \\
& Df & 435 \\
Sig. & .000 \\
\hline
\end{tabular}


Table 2. Eigenvalues and percent variance explained based on the Kaiser-criterion

\begin{tabular}{ccccccc}
\hline \multirow{2}{*}{ Component } & \multicolumn{5}{c}{ Initial eigenvalues } & \multicolumn{3}{c}{ Extraction sums of squared loadings } \\
& Total & \% of variance & Cumulative $(\%)$ & Total & \% of variance & Cumulative $(\%)$ \\
\hline 1 & 8.471 & 28.237 & 28.237 & 8.471 & 28.237 & 28.237 \\
2 & 2.370 & 7.901 & 36.138 & 2.370 & 7.901 & 36.138 \\
3 & 2.000 & 6.665 & 42.803 & 2.000 & 6.665 & 42.803 \\
4 & 1.790 & 5.965 & 48.768 & 1.790 & 5.965 & 48.768 \\
5 & 1.334 & 4.446 & 53.214 & 1.334 & 4.446 & 53.214 \\
6 & 1.123 & 3.743 & 56.957 & 1.123 & 3.743 & 56.957 \\
7 & 1.020 & 3.401 & 60.358 & 1.020 & 3.401 & 60.358 \\
8 & .934 & 3.114 & 63.473 & & & \\
9 & .899 & 2.996 & 66.468 & & & \\
10 & .820 & 2.733 & 69.202 & & & \\
11 & .798 & 2.661 & 71.863 & & & \\
12 & .745 & 2.484 & 74.347 & & & \\
13 & .712 & 2.372 & 76.719 & & & \\
14 & .660 & 2.200 & 78.919 & & & \\
15 & .628 & 2.093 & 81.011 & & & \\
16 & .604 & 2.013 & 83.024 & & & \\
17 & .579 & 1.929 & 84.953 & & & \\
18 & .509 & 1.698 & 86.651 & & & \\
19 & .498 & 1.661 & 88.312 & & & \\
20 & .457 & 1.523 & 89.835 & & & \\
21 & .412 & 1.373 & 91.207 & & & \\
22 & .380 & 1.267 & 92.474 & & & \\
23 & .371 & 1.238 & 93.711 & & & \\
24 & .336 & 1.120 & 94.832 & & & \\
25 & .313 & 1.044 & 95.876 & & & \\
26 & .308 & 1.025 & 96.901 & & & \\
27 & .276 & .919 & 97.820 & & & \\
28 & .243 & .808 & 98.628 & & & \\
29 & .213 & .709 & 99.337 & & & \\
30 & .199 & .663 & 100.000 & & & \\
\hline
\end{tabular}

Extraction method: Principal component analysis.

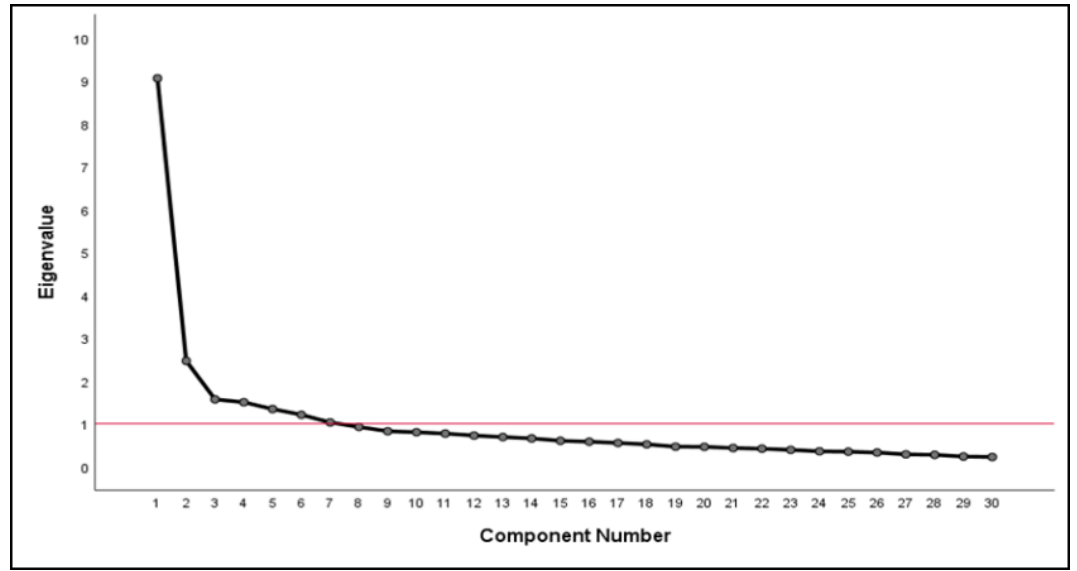

Figure 1. The scree plot result of the 30 indicators of ASI

The basis for retaining the four factors of stress based on the parallel analysis was the eigenvalues generated. If the eigenvalues generated using EFA are significantly greater than the eigenvalues produced using the parallel analysis, then that component is retained. It was evident in Table 3 that factors 1-4 have greater eigenvalues using EFA than the result using the parallel analysis. Meanwhile, the eigenvalues of factors 5-7 using EFA were smaller compared to the values in the parallel analysis. Thus, the first four factors were retained and were used in the succeeding analyses, such as the correlation analysis and regression analysis. These four factors explain $48.867 \%$ of the total variance in the data. 
Table 3. The four factors generated using the parallel analysis

\begin{tabular}{|c|c|c|c|c|c|}
\hline \multicolumn{3}{|c|}{ Parallel analysis } & Component & Eigenvalue & Parallel analysis \\
\hline \multicolumn{3}{|c|}{ Principal components } & & & \\
\hline \multicolumn{3}{|c|}{ Specifications for this run: } & 1 & 8.471 & 1.798549 \\
\hline Ncases & 250 & & & & \\
\hline Nvars & 30 & & 2 & 2.370 & 1.685693 \\
\hline Ndatsets & 100 & & & & \\
\hline Percent & 95 & & 3 & 2.000 & 1.592211 \\
\hline \multicolumn{6}{|c|}{ Random data eigenvalues } \\
\hline Root & Means & Prcntyle & 4 & 1.790 & 1.516107 \\
\hline 1. 000000 & 1.704413 & 1.798549 & & & \\
\hline 2. 000000 & 1.608355 & 1.685693 & 5 & 1.334 & 1.451280 \\
\hline 3. 000000 & 1.529370 & 1.592211 & & & \\
\hline 4. 000000 & 1.462114 & 1.516107 & 6 & 1.123 & 1.399023 \\
\hline 5. 000000 & 1.405280 & 1.451280 & & & \\
\hline 6. 000000 & 1.350618 & 1.399023 & 7 & 1.020 & 1.302606 \\
\hline 7. 000000 & 1.302922 & 1.348091 & & & \\
\hline 8. 000000 & 1.258218 & 1.302606 & & & \\
\hline 9. 000000 & 1.211977 & 1.249867 & & & \\
\hline 10. 000000 & 1.171233 & 1.205787 & & & \\
\hline 11.000000 & 1.128299 & 1.164894 & & & \\
\hline 12. 000000 & 1.089578 & 1.117337 & & & \\
\hline 13. 000000 & 1.052832 & 1.083927 & & & \\
\hline 14. 000000 & 1.017718 & 1.053896 & & & \\
\hline 15.000000 & 0.982103 & 1.014670 & & & \\
\hline
\end{tabular}

Table 4 shows the component matrix of the unrotated factor loadings of the four-factor solutions using parallel analysis. Likewise, Table 5 shows the component matrix of the rotated factor loadings of the four-factor solution. The discussion of each of the four factors of stress is shown in Table 5, namely: perceived personal stress, classroom stress, performance stress, and time management stress.

Table 4. Component matrix of the unrotated factor loadings of the four-factor solution

\begin{tabular}{|c|c|c|c|c|}
\hline \multirow[b]{2}{*}{ Indicators } & \multicolumn{4}{|c|}{ Component matrix } \\
\hline & $\begin{array}{l}\text { Factor 1: Perceived } \\
\text { personal stress }\end{array}$ & $\begin{array}{c}\text { Factor 2: Classroom } \\
\text { stress }\end{array}$ & $\begin{array}{c}\text { Factor 3: Performance } \\
\text { stress }\end{array}$ & $\begin{array}{c}\text { Factor 4: Time } \\
\text { management stress }\end{array}$ \\
\hline $\mathrm{X} 1$ & .294 & .566 & .085 & .361 \\
\hline $\mathrm{X} 2$ & .368 & .251 & .239 & .614 \\
\hline $\mathrm{X} 3$ & .425 & -.085 & .143 & .648 \\
\hline $\mathrm{X} 4$ & .444 & -.315 & -.133 & .362 \\
\hline $\mathrm{X} 5$ & .321 & .644 & .245 & -.162 \\
\hline X6 & .399 & .533 & .388 & -.103 \\
\hline$X 7$ & .490 & -.272 & .096 & -.047 \\
\hline $\mathrm{X} 8$ & .554 & .122 & -.054 & .151 \\
\hline X9 & .663 & .073 & .003 & .221 \\
\hline $\mathrm{X} 10$ & .466 & -.232 & -.014 & .246 \\
\hline $\mathrm{X} 11$ & .513 & -.262 & .539 & -.094 \\
\hline $\mathrm{X} 12$ & .490 & -.298 & .544 & .010 \\
\hline $\mathrm{X} 13$ & .511 & -.409 & -.148 & .133 \\
\hline $\mathrm{X} 14$ & .551 & .143 & -.038 & -.076 \\
\hline $\mathrm{X} 15$ & .517 & .363 & -.382 & -.090 \\
\hline $\mathrm{X} 16$ & .571 & .295 & -.214 & .124 \\
\hline $\mathrm{X} 17$ & .528 & .018 & -.239 & .168 \\
\hline $\mathrm{X} 18$ & .423 & .114 & -.212 & -.125 \\
\hline X19 & .539 & .280 & -.244 & -.206 \\
\hline $\mathrm{X} 20$ & .582 & .031 & -.147 & -.333 \\
\hline $\mathrm{X} 21$ & .554 & -.243 & .184 & -.160 \\
\hline $\mathrm{X} 22$ & .613 & .051 & -.134 & -.078 \\
\hline X23 & .552 & -.393 & -.187 & -.013 \\
\hline X24 & .663 & .117 & -.274 & -.079 \\
\hline X25 & .665 & -.182 & -.039 & -.154 \\
\hline X26 & .656 & -.066 & -.251 & .158 \\
\hline $\mathrm{X} 27$ & .627 & -.152 & .280 & -.203 \\
\hline $\mathrm{X} 28$ & .586 & -.140 & -.309 & -.292 \\
\hline X29 & .502 & .225 & .447 & -.217 \\
\hline X30 & .607 & -.127 & .301 & -.218 \\
\hline
\end{tabular}

Extraction method: Principal component analysis 
Table 5. Component matrix of the rotated factor loadings of the four-factor solution

\begin{tabular}{|c|c|c|c|c|c|}
\hline & \multirow{2}{*}{ Indicators } & \multicolumn{4}{|c|}{ Component } \\
\hline & & Factor 1 & Factor 2 & Factor 3 & Factor 4 \\
\hline $\mathrm{X} 24$ & Doing things well in all the subjects in the course & .728 & & & \\
\hline $\mathrm{X} 28$ & $\begin{array}{l}\text { The fact that my parents keep reminding and following up about my studies } \\
\text { (e.g., whether I do my homework and activities, my grades.) }\end{array}$ & .684 & & & \\
\hline $\mathrm{X} 26$ & Making leisure time and academic work compatible & .663 & & & \\
\hline $\mathrm{X} 15$ & Obtaining high grades in different subjects & .661 & & & \\
\hline $\mathrm{X} 19$ & Finishing the course on time & .636 & & & \\
\hline $\mathrm{X} 20$ & Family pressure to obtain good grades & .634 & & & \\
\hline $\mathrm{X} 25$ & Family discussion and conflicts caused by my studies & .622 & & & \\
\hline $\mathrm{X} 22$ & Keeping up with the academic activities and task & .621 & & & \\
\hline $\mathrm{X} 16$ & Future academic and professional perspective & .605 & & & \\
\hline $\mathrm{X} 17$ & $\begin{array}{l}\text { Choosing subjects in the coming course (e. g. making sure to pass the } \\
\text { prerequisite subjects) }\end{array}$ & .548 & & & \\
\hline $\mathrm{X} 23$ & My relationship with my classmates & .542 & & & \\
\hline $\mathrm{X} 14$ & Too much responsibility to fulfill my obligations & .534 & & & \\
\hline $\mathrm{X} 8$ & Doing a task that involves looking for information and writing & .508 & & & \\
\hline $\mathrm{X} 18$ & Getting or keeping a scholarship grant & .494 & & & \\
\hline $\mathrm{X} 11$ & Problems or conflicts with teachers & & .756 & & \\
\hline $\mathrm{X} 12$ & Problems or conflicts with classmates & & .734 & & \\
\hline $\mathrm{X} 27$ & Teachers' pressure about my work and behavior & & .711 & & \\
\hline $\mathrm{X} 30$ & The fact that my classmates think I'm not a good student & & 698 & & \\
\hline $\mathrm{X} 21$ & Lack of support from my teachers & & .642 & & \\
\hline $\mathrm{X} 7$ & Competition among classmates & & .543 & & \\
\hline X29 & Doing poorly on an exam & & .532 & & \\
\hline $\mathrm{X} 13$ & Being able to attend all the classes & & .472 & & \\
\hline $\mathrm{X} 3$ & Class participation (e.g., asking the question) & & & .777 & \\
\hline $\mathrm{X} 2$ & Presentations of work in class & & & .714 & \\
\hline $\mathrm{X} 9$ & The task of studying (e.g., meeting established schedules, level of effort) & & & .588 & \\
\hline $\mathrm{X} 4$ & Dealing with the teacher outside of class (e.g., in homeroom, office visits) & & & .559 & \\
\hline $\mathrm{X} 10$ & Working with classmates on tasks in class & & & .487 & \\
\hline $\mathrm{X} 5$ & Academic overload (having too many exams and tasks to do) & & & & .721 \\
\hline X6 & Lack of time to fulfill all the activities we are asked to do & & & & .687 \\
\hline $\mathrm{X} 1$ & Taking exams & & & & .548 \\
\hline
\end{tabular}

Extraction method: Principal component analysis; Rotation method: Promax with Kaiser normalization.

\subsubsection{Perceived personal stress}

When an individual acknowledges that their resources are no longer sufficient to meet the obligations, they experience stress. As a result, it might be regarded as a perceived disparity between the demands of daily life and the students' ability to respond [13]. In this study, perceived personal stress included doing well in all the subjects in the course, constant monitoring of parents regarding their studies, making leisure time and academic work compatible, obtaining high grades in different subjects, and finishing the course on time.

Furthermore, Heinen, Bullinger, and Kocalevent [13] by highlighting that among personal resources, optimism, and self-efficacy have all been studied as potential stress buffers. In both the general population and students, higher levels of optimism were linked to lower levels of felt personal stress. In other words, students are influenced if they are harassed at home by family or any of their friendly ties. Individuals that suffer high levels of stress require more social support and resources, such as interpersonal support. As stated by Akman [14] that parents did not provide emotional support to students who were under a lot of stress. This revealed that a positive family relationship could provide social support and resources to help students cope with their difficulties [15].

Stressed people are less likely to apply cognitive reappraisal procedures and positively evaluate their surroundings because they are focused with their worries [15]. Jeon, Kwon, and Choi [15] further noted that if this is the case, professional assistance may not be available to the pupils. Perceived personal stress, in particular, was found to limit the protective factors' favorable impact on students' response to their academic work. According to Jain and Singhai [16], students are routinely acclimated in a way that makes them fearful of enduring various problems because the focus is solely on academics rather than the mental evolution of a go-getter. As a result, positive reinforcements should be offered to pupils in order to drive them in their academic pursuits. Dimitrov [17] also emphasized that the students' welfare should be given top priority, with food, exercise, employment, and recreation being some of the areas to concentrate on. 


\subsubsection{Classroom stress}

The second factor identified is classroom stress. The teachers' apprehension on students' performance, their support, and their affection all lead to mutual trust in teacher-student relations; thus, increasing the student's commitment to the school [14], [18]. Previous researcher [14] posited that a healthy classroom relationship can lead to academic and behavioral development, while a hostile classroom environment can lower students' interest in school and their academic performance [14], [19]. Akman [14] further noted that classroom stress is caused by both failure and disappointed expectations.

As a result, if problems or conflicts arise in the classroom, such as those between teachers and students, there will be enough anxiety to cause classroom stress. A contrasting setting might produce a poor classroom atmosphere because learning is built on mutual trust [14]. Lätsch [20] emphasized that classroom competition raises challenges; yet, these issues may lead to school-based prevention and intervention techniques that help pupils do better in school.

\subsubsection{Performance stress}

Kosir [21] highlighted that a breakdown of the equilibrium between the cognitive-emotionalenvironmental system and external influences is defined as stress. These external circumstances also contributed to the cognitive and emotional system's equilibrium, depending on an individual's performance capacity (e.g., coping resources) at the time. Students became overwhelmed by internal or external forces as a result of the interruption, producing further performance stress.

It's worth noting that students are aware of their teacher interactions and conversations even after class. Office visits or impromptu meetings in the school lobby or off-campus were examples of these occurrences. These experiences, which were once distressing, are now potentially dangerous because they call into question one's daily assumptions and preconceptions [22]. Lätsch [20] highlighted Lazarus and Folkman [23] notion that small and insignificant happenings in everyday life might induce stress. If this is the case, teachers should recognize that students are caught up in their everyday struggles and be more attentive to their feelings. These annoyances were characterized as dynamic processes (transactions) that have an impact on a conscientious, emotional, and active person [20].

\subsubsection{Time management stress}

As previously stated, one source of stress for students was the amount of time they spent on learning exercises and assignments [20]. They become agitated and anxious when they believe they do not have enough time to complete all of their activities. Several events in a person's life resulted in negative feelings such as anger, irritation, and anxiousness, which exacerbated stress [16]. Juggling all of one's obligations, from academics to extracurricular activities, is one of these events that may overwhelm students, resulting in a difficult existence. Heavy academic workloads, little study time while continually racing to meet another deadline, and taking and preparing for tests are all reasons why students are anxious about their time management skills [16], [24], [25]. These can elicit a sense of threat [26], and as a result, will be perceived as stressful by the students.

According to Malach-Pines and Keinan [27], stress is the awareness of inconsistency between external burdens (stressors) and a person's ability to meet particular obligations. Part of what teachers should do is focus on allowing pupils to take care of their own welfare and well-being [17]. As a result, if students can effectively manage their time and avoid procrastination, there will be sufficient time for leisure activities.

\subsection{Students' level of academic stress}

To determine the level of academic stress of college students, the mean, reflected in Table 6. As revealed in Table 6, the students' level of academic stress is within a moderate level. This result was corroborated with the result of previous studies [12], [28]. Both studies revealed that almost all of their respondents have experienced a moderate level of stress. Academic stress is a serious issue that requires attention. Stress has been linked to a variety of factors, including age, degree pursued, GPA, perceptions of English language competence, academic (exam preparation), family and class pressure, grade competitions, and problem-solving skills among others [24], [25], [29]. Furthermore, it has been linked to schizophrenia, depression, suicide, and a variety of maladaptive behaviors such as delinquency and crime [30].

If a student cannot properly manage with academic stress, substantial psychosocial and mental health implications may result [31]. Methods or other coping strategies for stress must be widely accessible among students in order to minimize the negative impact of stress on students' learning and performance. 
Table 6. Level of academic stress

\begin{tabular}{lcc}
\hline \multicolumn{1}{c}{ Factor } & Mean & Level of stress \\
\hline Perceived personal stress & 3.1594 & Moderate \\
Classroom stress & 2.8895 & Moderate \\
Performance stress & 3.1432 & Moderate \\
Time management stress & 3.8360 & High \\
\multicolumn{1}{c}{ Overall } & 3.2570 & Moderate \\
\hline Cut off point: $1.00-1.79$ (Very low); $1.80-2.59$ (Low); \\
2.60-3.39 (Moderate) 3.40-4.19 (High); 4.20-5.00 (Very high)
\end{tabular}

\subsection{Correlation analysis of the factors and English grades}

The result of the correlation analysis using Pearson $r$ between and among the four factors of stress include: perceived personal stress; classroom stress; performance stress; and time management stress are provided in Table 7. As revealed in Table 7, perceived personal stress was significantly correlated with classroom stress $(r=0.520, p<0.01)$ and performance stress $(r=0.437, p<0.01)$. Moreover, classroom stress was significantly correlated with performance stress $(\mathrm{r}=0.342, \mathrm{p}<0.01)$. This result signified that as the level of one of these three factors increase, there is a significant corresponding increase in the levels of the other two factors. However, time management stress was not significantly correlated with the other three factors.

On the other hand, grades in English were not significantly correlated with the four dimensions of academic stress. This showed that an increase or a decrease in the levels of these factors does not necessarily imply an increase or decrease in their grades in English. As shown and discussed earlier, students had a moderate level of academic stress and since the academic stress did not significantly impact their grades in English, this could mean that students had ways to cope with the various academic stress. These stress experiences were modulated in a dynamic process by appraisal and coping, wherein individuals who perceive stress examined and used their presently available coping resources [13], [23]. Therefore, coping mechanisms in stress might be the reason behind a moderate level of academic stress and the non-significant relationship between academic stress and English performance.

Table 7. Result of the correlation analysis of the factors and the English grades

\begin{tabular}{cccccc}
\hline & Factor 1 & Factor 2 & Factor 3 & Factor 4 & Grades \\
\hline F1 & 1 & & & & \\
F2 & $.520^{* *}$ & 1 & & & \\
F3 & $.437^{* *}$ & $.342^{* *}$ & 1 & & \\
F4 & -.014 & -.104 & .014 & 1 & \\
Grades & -.036 & -.089 & .033 & .044 & 1 \\
\hline **Significant at 1\% level & & & &
\end{tabular}

\section{CONCLUSION}

Students in college were shown to experience a moderate degree of academic stress, which was influenced by four factors: perceived personal stress, classroom stress, performance stress, and time management stress. The students' stress experiences were regulated through coping mechanisms that they used to manage their academic stress and move towards carrying out their responsibilities despite the existence of these stressors, which recounts people's ability to exert self-control.

As implication of these findings, institutions should implement institution-based prevention and intervention initiatives to reduce students' academic stress, which may help them perform better in school. Teachers, for example, should recognize that students are engrossed in their daily struggles, be more attentive to their sentiments, and allow students to attend to their own welfare and well-being, allowing them to balance academic and recreational activities.

\section{REFERENCES}

[1] C. Stangor and J. Walinga, Introduction to Psychology: 1st Canadian edition. Victoria, B.C: BCcampus, 2014.

[2] J. Yates, Managing Stress: A Businessperson's Guide. New York: AMACOM, 1979.

[3] J. M. Ivancevich and M. T. Matteson, Stress and Work: A Managerial Perspective. Scott, Foresman and Company, Chicago, IL. 1980.

[4] M. M. Aafreen, V. V. Priya, and R. Gayathri, "Effect of Stress on Academic Performance of Students in Different Streams," Drug Invention Today, vol. 10, no. 9, pp. 1776-1780, 2018.

[5] L. Pariat, A. Rynjah, and M. G. Kharjana Joplin, "Stress Levels of College Students: Interrelationship between Stressors and Coping Strategies," IOSR Journal of Humanities and Social Science (IOSR-JHSS), vol. 19, no. 8, pp. 40-46, 2014, doi: 10.9790/0837-19834046. 
[6] R. Misra, M. McKean, S. West, and T. Russo, "Academic Stress of College Students: Comparison of Student and Faculty Perceptions” College Student Journal, vol. 34, no. 2, pp. 236-245, 2000.

[7] B. T. Shaikh, et al., "Students, stress and coping strategies: A case of Pakistani medical school," Education for Health, vol. 17, no. 3, pp. 346-353, 2004, doi: 10.1080/13576280400002585.

[8] S. E. Wilks, "Resilience Amid Academic Stress: The Moderating Impact of Social Support among Social Work Students," Advances in Social Work, vol. 9, no. 2, pp. 106-125, 2008.

[9] C. Gbollie and H. P. Keamu, "Student Academic Performance: The Role of Motivation, Strategies, and Perceived Factors Hindering Liberian Junior and Senior High School Students Learning," Education Research International, vol. 2017, pp. 1-12, 2017, doi: 10.1155/2017/1789084.

[10] W. R. Louis, M. K.-H. Chan, and S. Greenbaum, "Stress and the Theory of Planned Behavior: Understanding Healthy and Unhealthy Eating Intentions," Journal of Applied Social Psychology, vol. 39, no. 2, pp. 472-493, 2009, doi: 10.1111/j.1559-1816.2008.00447.x.

[11] M. Shadi, N. Peyman, A. Taghipour, and H. Tehrani, "Predictors of Academic Stress and its Determinants among Students Based on the Theory of Planned Behavior," Fundamentals of Mental Health, vol. 20, no. 1, pp. 87-98, 2018, doi: 10.22038/JFMH.2017.24923.2279.

[12] R. García-Ros, F. Pérez-González, and J. M. Tomás, "Development and Validation of the Questionnaire of Academic Stress in Secondary Education: Structure, Reliability, and Nomological Validity,” International Journal of Environment Research Public Health, vol. 15, no. 9, 2018, doi: 10.3390/ijerph15092023.

[13] I. Heinen, M. Bullinger, and R.-D. Kocalevent, "Perceived Stress in First-Year Medical Students - Associations with Personal Resources and Emotional Distress," BMC Medical Education, vol. 17, no. 4, pp. 1-14, 2017, doi: 10.1186/s12909-016-0841-8.

[14] Y. Akman, "The role of classroom management on confidence in teachers and educational stress," International Journal of Contemporary Educational Research, vol. 7, no. 1, pp. 335-345, 2020, doi: 10.33200/ijcer.687109.

[15] L. Jeon, K.-A. Kwon, and J. Y. Choi, "Family child care providers' responsiveness toward children: The role of professional support and perceived stress," Children and Youth Services Review, vol. 94, pp. 500-510, 2018, doi: 10.1016/j.childyouth.2018.08.023.

[16] G. Jain and M. Singhai, "Academic Stress amongst Students: A Review of the literature," Prestige e-Journal of Management and Research, vol. 5, no. 1, pp. 58-67, 2018.

[17] G. Dimitrov, "A Study on the Impact of Academic Stress among College Students in India," Ideal Research, vol. 2, no. 4, pp. 21-35, 2017.

[18] A. B. Brewster and G. L. Bowen, "Teacher Support and the School Engagement of Latino Middle and High School Students at Risk of School Failure," Child and Adolescent Social Work Journal, vol. 21, no. 1, pp. 47-67, 2004.

[19] J. Sun, M. P. Dunne, X. Hou, and A. Xu, "Educational Stress among Chinese Adolescents: Individual, Family, School, and Peer Influences,” Educational Review, vol. 65, no. 3, pp. 284-302, 2013.

[20] A. Lätsch, "Do perceived helpfulness and competition in classroom contexts moderate or mediate the association between perceived stress and socio-emotional strengths and difficulties from early to middle adolescence?" Learning and Individual Differences, vol. 58, pp. 31-40, 2017, doi: 10.1016/j.lindif.2017.07.006.

[21] K. Kosir, "Two sides of the same coin? The role of rumination and reflection in elementary school teachers' classroom stress and burnout," Teaching and Teacher Education, vol. 47, pp. 131-141, 2015, doi: $10.1016 / \mathrm{j}$. tate.2015.01.006.

[22] G. Ramirez, I. M. McDonough, and L. Jin, "Classroom stress promotes motivated forgetting of mathematics knowledge," Journal of Educational Psychology, vol. 109, no. 6, pp. 812-825, 2017, doi: 10.1037/edu0000170.

[23] R. S. Lazarus and S. Folkman, Stress, Appraisal, and Coping. New York: Springer Publishing Company, 1984.

[24] M. Z. Bataineh, "Academic Stress among Undergraduate Students: The Case of Education Faculty at King Saud University," International Interdisciplinary Journal of Education, vol. 2, no. 1, pp. 82-88, 2013.

[25] D. Yikealo, W. Tareke, and I. Karvinen, "The level of stress among college students: A case in the College of Education, Eritrea Institute of Technology," Open Science Journal, vol. 3, no. 4, pp. 1-18, 2018.

[26] S. M. Auerbach and S. E. Grambling, Stress Management: Psychological Foundations. U.S.A, Prentice-Hall, Inc., 1998.

[27] A. Malach-Pines and G. Keinan, "Stress and burnout in Israeli police officers during Palestinian uprising (Intifada)," International Journal of Stress Management, vol. 14, no. 2, pp. 160-174, 2007, doi: 10.1037/10725245.14.2.160

[28] H. Elias, "Stress and Academic Achievement among Undergraduate Students in Universiti Putra Malaysia," Procedia-Social and Behavioral Sciences, vol. 29, pp. 646-655, 2011, doi: 10.1016/j.sbspro.2011.11.288.

[29] A. Zajacova, S. M. Lynch, and T. J. Espenshade "Self-efficacy, stress, and academic success in college," Research in Higher Education, vol. 46, no. 6, pp. 677-706, 2005, doi: 10.1007/s11162-004-4139-z.

[30] T. Fryers and B. Traolach, "Childhood determinants of adult psychiatric disorder," Clinical Practice \& Epidemiology in Mental Health, vol. 9, pp. 1-50, 2013, doi: 10.2174/1745017901309010001.

[31] M. C. Pascoe, S. E. Hetrick, and A. G. Parker, "The impact of stress on students in secondary school and higher education," International Journal of Adolescence and Youth, vol. 25, no. 1, pp. 104-112, 2019, doi: $10.1080 / 02673843.2019 .1596823$. 